\title{
Feedback Regulation of Bile-Acid Synthesis in the Rat Differing Effects of Taurocholate and Tauroursocholate
}

\author{
S. Shefer, L. Nguyen, G. Salen, A. K. Batta, D. Brooker, F. G. Zaki, I. Rani, and G. S. Tint \\ Department of Medicine and the Sammy Davis, Jr. National Liver Institute, University of Medicine and Dentistry of New Jersey- \\ New Jersey Medical School, Newark, New Jersey 07103; Veterans Administration Medical Center, East Orange, \\ New Jersey 07109; and Squibb Institute for Medical Research, Princeton, New Jersey 08540
}

\begin{abstract}
We studied the effect of the orientation of the 7-hydroxyl group in taurocholate $(7 \alpha)$ and tauroursocholate $(7 \beta)$ on the feedback regulation of bile-acid synthesis and its rate-controlling enzyme, cholesterol $7 \alpha$-hydroxylase, in bile-fistula rats. To ensure a constant supply of cholesterol and to label newly synthesized bile acids, $R S\left[2-{ }^{14} \mathrm{C}\right]$ mevalonolactone was infused intraduodenally at $154 \mu \mathrm{mol} / \mathrm{h}$ before and during bile-acid infusion. Mevalonolactone inhibited hydroxymethyl-glutaryl CoA reductase activity $90 \%$ but did not increase bile-acid synthesis and cholesterol $7 \alpha$-hydroxylase activity. When sodium taurocholate was infused at the rate of $27 \mu \mathrm{mol} / 100 \mathrm{~g}$ rat per $h$ (equivalent to the hourly hepatic bile-acid flux), bile-acid synthesis decreased $82 \%$ and cholesterol $7 \alpha$-hydroxylase activity declined $78 \%$. This inhibitory effect was observed in the absence of hepatic damage. In contrast, sodium tauroursocholate infused at the same rate did not decrease bile-acid synthesis nor cholesterol $7 \boldsymbol{\alpha}$-hydroxylase activity. Hepatic cholesterol content rose $36 \%$ with sodium taurocholate but did not change during sodium tauroursocholate administration. These results demonstrate that the feedback inhibition of bile-acid synthesis is mediated through the regulation of cholesterol $7 \alpha$-hydroxylase. In these experiments, taurocholate was a far more potent inhibitor than its $7 \beta$-hydroxy epimer, tauroursocholate. ( $J$.

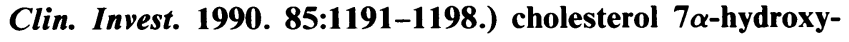
lase - mevalonic acid $\bullet$ hydroxymethylglutaryl coenzyme A reductase $\bullet$ bile fistula $\bullet$ bile composition
\end{abstract}

\section{Introduction}

Cholesterol ${ }^{1}$ is the obligate precursor of bile acids in mammals (1). According to current information, the conversion of cho-

Address reprint requests to Dr. S. Shefer, UMDNJ-New Jersey Medical School, Department of Medicine, MSB, Rm. H-534, 185 South Orange Avenue, Newark, NJ 07103-2757.

Received for publication 10 May 1989 and in revised form 14 November 1989.

1. The following systematic names are given to compounds referred to by trivial names: cholesterol, 5 -cholesten- $3 \beta$-ol; $7 \alpha$-hydroxycholes-

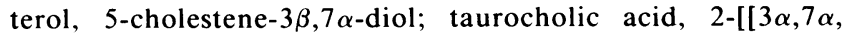
$12 \alpha$-trihydroxy-24-oxo- $5 \beta$-cholan-24-yl]amino]ethanesulfonic acid; tauroursocholic acid, 2-[[3 $\alpha, 7 \beta, 12 \alpha$-trihydroxy-24-oxo-5 $\beta$-cholan-24yl]amino]ethanesulfonic acid; lithocholic acid, $3 \alpha$-hydroxy- $5 \beta$-cholan24 -oic acid; deoxycholic acid, $3 \alpha, 12 \alpha$-dihydroxy-5 $\beta$-cholan-24-oic acid; chenodeoxycholic acid, $3 \alpha, 7 \alpha$-dihydroxy-5 $\beta$-cholan-24-oic acid; $\alpha$-muricholic acid, $3 \alpha, 6 \beta, 7 \alpha$-trihydroxy- $5 \beta$-cholan-24-oic acid; cholic

J. Clin. Invest.

(C) The American Society for Clinical Investigation, Inc. 0021-9738/90/04/1191/08 \$2.00

Volume 85, April 1990, 1191-1198 lesterol to $7 \alpha$-hydroxycholesterol is the rate-determining step of bile-acid synthesis and is catalyzed by the enzyme cholesterol $7 \alpha$-hydroxylase $(\mathrm{CH} 7 \alpha \mathrm{H})^{2}$ which is located in the hepatic smooth endoplasmic reticulum (2-5). Although much evidence suggests that the enterohepatic flux of bile acids through the liver controls bile-acid synthesis $(3,6-8)$, there is still some controversy concerning the specific mechanism. The following questions need to be considered: $(a)$ whether bile-acid structure is important in the feedback regulation of bile-acid synthesis, in particular, the orientation of the hydroxyl group at $\mathrm{C}-7$; and $(b)$ whether this feedback inhibition is mediated via the suppression of $\mathrm{CH} 7 \alpha \mathrm{H}$, the rate-controlling enzyme of bile-acid synthesis. In order to answer these questions, bileacid synthesis was studied in the bile-fistula rat where synthesis was maximized by the interruption of the enterohepatic circulation and depletion of the endogenous bile-acid pool. ${ }^{14} \mathrm{C}$-Labeled mevalonic acid (Mev) was infused continuously to provide optimal amounts of newly synthesized cholesterol to serve as substrate for bile-acid synthesis and to label endogenous bile acids. Taurocholate (TCA) or its $7 \beta$-epimer tauroursocholate (TUCA) was administered in amounts equal to the hepatic flux of bile acids through the liver, and the production of endogenous bile acids was correlated with the activity of $\mathrm{CH} 7 \alpha \mathrm{H}$. The objective of this model was to uncouple bile-acid synthesis from hydroxymethylglutaryl $\mathrm{CoA}$ reductase (HMGR) activity by providing an adequate supply of cholesterol for conversion into bile acids.

\section{Methods}

Animals. Male Sprague Dawley rats (Taconic Farms, Inc., Germantown, NY) weighing 200-250 g were fed ad lib. rat chow (Purina Mills, Inc., St. Louis, MO). After the induction of anesthesia by sodium pentobarbital (nembutal, $39 \mathrm{mg} / \mathrm{kg}$, i.p.), the common bile duct was exposed, cannulated with a polyethelene catheter (outer diameter $0.024 \mathrm{in}$.) and exteriorized through a stab wound in the lower part of the abdomen. Bile was allowed to drain freely and was collected in 2-h fractions with a fraction collector. A second polyethylene infusion cannula was placed into the proximal end of the duodenum and a continuous infusion of a glucose-electrolyte solution (Ringer-Tyrode) supplemented with $\mathrm{NaHCO}_{3}(25 \mu \mathrm{eq} / \mathrm{h})(9)$ was delivered into the

acid, $3 \alpha, 7 \alpha, 12 \alpha$-trihydroxy-5 $\beta$-cholan-24-oic acid; ursodeoxycholic acid, $3 \alpha, 7 \beta$-dihydroxy-5 $\beta$-cholan-24-oic acid; ursocholic acid, $3 \alpha$, $7 \beta$-12 $\alpha$-trihydroxy-5 $\beta$-cholan-24-oic acid; $\beta$-muricholic acid, $3 \alpha, 6 \beta, 7 \beta$-trihydroxy-5 $\beta$-cholan-24-oic acid.

2. Abbreviations used in this paper: $\mathrm{CA}$, cholic acid; $\mathrm{CDCA}$, chenodeoxycholic acid; $\mathrm{CH} 7 \alpha \mathrm{H}$, cholesterol $7 \alpha$-hydroxylase; GLC, gas-liquid chromatography; HMGR, hydroxymethylglutaryl CoA reductase; $\alpha$-MCA, $\alpha$-muricholic acid; $\beta$-MCA, $\beta$-muricholic acid; Mev, mevalonic acid or mevalonolactone; TCA, taurocholate; TLC, thin-layer chromatography; TUCA, tauroursocholate; UCA, ursocholic acid; UDCA, ursodeoxycholic acid. 
duodenum at a fixed rate of $1.2 \mathrm{ml} / \mathrm{h}$ by an infusion pump (Harvard Apparatus Co., Inc., S. Natick, MA). Also, the rats consumed rat chow ad lib. When bile-acid synthesis was maximally stimulated, $\left[2-{ }^{14} \mathrm{C}\right]-$ mevalonolactone (New England Nuclear, Boston, MA) was added to the duodenal infusion solution at a rate of $154 \mu \mathrm{mol} / \mathrm{h}\left(1.45 \times 10^{4}\right.$ $\mathrm{dpm} / \mu \mathrm{mol}$ ) to provide a constant supply of substrate for bile-acid synthesis and to label the newly synthesized bile acids. When the label had equilibrated with the newly synthesized bile acids, as evidenced by a constant specific activity, TCA or TUCA was added to the infusion solution at a rate of $27 \mu \mathrm{mol} / 100 \mathrm{~g}$ rat per $\mathrm{h}$, equivalent to the hourly hepatic bile-acid flux (10). The sodium salt of TCA, purchased from Calbiochem-Behring Corp., San Diego, CA, was recrystallized three times from ethanol/ethyl acetate and was $>98 \%$ pure by thin-layer chromatography (TLC) (11). Ursocholic acid (UCA; a gift from Gipharmex, Milan, Italy) was conjugated with taurine according to the method of Tserng et al. (12), and the taurine conjugate was $>98 \%$ pure by TLC (silica gel G; solvent system, chloroform/methanol/acetic acid/water, 13:5:2:1 vol/vol/vol/vol; $\boldsymbol{R}_{\mathrm{f}}=0.97$ and 0.53 for UCA and TUCA, respectively). Animals were killed by decapitation after $24-$ or 40-h infusion with the tested bile acids, and livers were excised for morphology study, analysis of hepatic cholesterol content, and assays for microsomal $\mathrm{HMGR}$ and $\mathrm{CH} 7 \alpha \mathrm{H}$ activities. In a number of experiments, the infusion of bile acids was discontinued after $40 \mathrm{~h}$ but the $\left[{ }^{14} \mathrm{C}\right]$ mevalonolactone infusion was continued for an additional $40 \mathrm{~h}$ to test the reversibility of the bile-acid effect.

Determination of biliary cholesterol and bile acids. Biliary cholesterol was extracted with $n$-hexane from $100 \mu l$ bile using sitosterol as recovery standard and quantitated by capillary gas-liquid chromatography (GLC) as described previously (13). Biliary bile acids were deconjugated and methylated (11) using tauroursodeoxycholic acid as recovery standard. They were then quantitated as trimethylsilyl ether derivatives by capillary GLC on a WCOT fused silica column $(0.22$ $\mathrm{mm} \times 25 \mathrm{~m}$ ) coated with a $0.12-\mu \mathrm{m}$ film of CP Sil 5 CB (Chrompak, Inc., Bridgewater, $\mathrm{NJ}$ ). The chromatograph was operated at column temperature of $265^{\circ} \mathrm{C}$ and a helium flow of $1.3 \mathrm{ml} / \mathrm{min}$. The retention times of bile acids relative to that of the internal standard $5 \alpha$-cholestane (13.1 min) were: deoxycholic acid, 1.49; chenodeoxycholic acid (CDCA), 1.54; $\alpha$-muricholic acid ( $\alpha$-MCA), 1.56; cholic acid (CA), 1.57; ursodeoxycholic acid (UDCA), 1.63; UCA, 1.73; and $\beta$-muricholic acid ( $\beta$-MCA), 1.83 (Fig. 1).

In TCA-infused rats, the amounts of endogenous CA could not be measured directly by GLC but were calculated from the total counts of the CA fraction divided by the specific activity of CA before TCA infusion. This specific activity was determined by a combination of TLC (11), capillary GLC as described above, and liquid scintillation counting (IN/US SL 4000, Fairfield, NJ) of the bile acids. This method was validated by comparing the mass of $\mathrm{CA}$ measured directly by

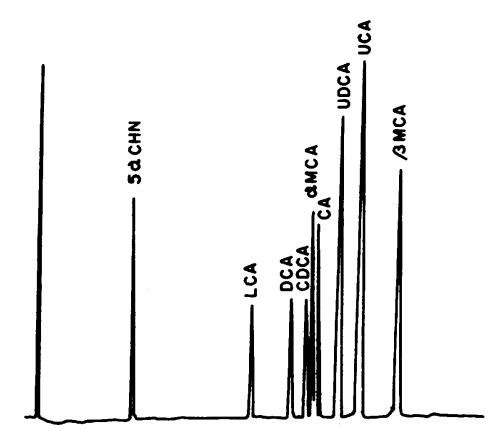

Figure 1. Capillary gas liquid chromatogram of trimethylsilylether methyl ester derivatives of bile acids. The bileacid derivatives were separated by capillary GLC. $5 \alpha$-Cholestane $(5 \alpha-\mathrm{CHN})$ and UDCA were the internal and recovery standards, respectively. The derivatized bile acids separated were: LCA, lithocholic acid; DCA, deoxycholic acid;

\begin{tabular}{|c|c|c|}
\hline $01 \frac{1}{10}$ & $\begin{array}{l}1 / 1 \\
\text { Time, } \quad 18 \text { in }\end{array}$ & $\frac{1}{24}$ \\
\hline
\end{tabular}

CDCA, chenodeoxycholic acid; $\alpha$-MCA, $\alpha$-muricholic acid; CA, cholic acid; UCA, ursocholic acid; and $\beta$-MCA, $\beta$-muricholic acid. capillary GLC with the mass of CA calculated from specific activities in experiments where mevalonolactone or mevalonolactone + TUCA were infused.

Determination of free and esterified hepatic cholesterol. An aliquot $(0.5 \mathrm{ml})$ of whole liver homogenate or microsomes was extracted with $20 \mathrm{vol}$ of chloroform/methanol $(2: 1, \mathrm{vol} / \mathrm{vol})$ after the addition of $\left[{ }^{3} \mathrm{H}\right]$ cholesterol and $\left[{ }^{3} \mathrm{H}\right]$ cholesterol oleate $\left(1.1 \times 10^{6} \mathrm{dpm}\right.$ each $)$ as recovery standards. The extract was separated by TLC on silica gel $\mathbf{G}$ with hexane/ethyl ether/acetic acid (85:15:0.5, vol/vol/vol). The bands corresponding to free and esterified cholesterol fractions $\left(R_{\mathrm{f}}=0.09\right.$ and 0.87 , respectively) were scraped and eluted with ethyl acetate/methanol $(85: 15, \mathrm{vol} / \mathrm{vol})$. Both fractions were counted and analyzed by GLC as described above after hydrolysis of the esterified cholesterol at $70^{\circ} \mathrm{C}$ for $1 \mathrm{~h}$ in $10 \%$ ethanolic $\mathrm{KOH}$ and extraction with hexane. The specific activity of the microsomal $\left[{ }^{14} \mathrm{C}\right]$ cholesterol was determined from the total $\left[{ }^{14} \mathrm{C}\right]$ counts divided by the mass of cholesterol as determined by GLC.

Rat liver histology. Liver specimens obtained after $24 \mathrm{~h}$ of treatment (Mev, Mev + TCA, or Mev + TUCA) were processed for light and electron microscopic evaluation as described previously (2).

Enzyme assays. Hepatic microsomes were prepared by differential ultracentrifugation (14). The assay for $\mathrm{CH} 7 \alpha \mathrm{H}$ in intact microsomes was carried out based on the isotope incorporation method by Shefer et al. (14). A mixture $(0.5 \mathrm{ml})$, containing $200 \mu \mathrm{M}\left[{ }^{14} \mathrm{C}\right]$ cholesterol solubilized in $0.15 \%$ Triton X-100, 2 U NADPH-cytochrome $P-450$ reductase (15), and 0.1-1.0 $\mu \mathrm{M}$ microsomal cytochrome P-450, was preincubated $2 \mathrm{~min}$ at $37^{\circ} \mathrm{C}$. The reaction was initiated with $0.6 \mu \mathrm{mol}$ $\mathrm{NADPH}$, incubated for $10 \mathrm{~min}$ at $37^{\circ} \mathrm{C}$, and stopped with $7.5 \mathrm{ml}$ dichloromethane/ethanol (5:1, vol/vol). The labeled $7 \alpha$-hydroxycholesterol formed was determined as previously described (14). In TCAinfused rats, which showed increased hepatic cholesterol concentration, $\mathrm{CH} 7 \alpha \mathrm{H}$ activity was also assayed after removal of endogenous cholesterol by acetone treatment $(16,17)$. This method has been shown to give comparable results to that of intact microsomes (17). The assay for expressed HMGR activity was based on methods by Shefer et al. (6) and Harwood et al. (18). Briefly, 50-200 $\mu \mathrm{g}$ microsomal protein is preincubated at $37^{\circ} \mathrm{C}$ for $5 \mathrm{~min}$ in a final volume of $150 \mu \mathrm{l}$ buffer (50 $\mathrm{mM}$ Tris, $68 \mathrm{mM}$ EDTA, $5 \mathrm{mM}$ DTT, and $70 \mathrm{mM} \mathrm{NaF}, \mathrm{pH} 7.5$ ) containing an NADPH-generating system (34 mM NADP ${ }^{+}, 30 \mathrm{mM}$ glucose-6-phosphate, and $0.3 \mathrm{U}$ glucose 6-phosphate dehydrogenase) and $40,000 \mathrm{dpm}\left[{ }^{3} \mathrm{H}\right]$ mevalonolactone as internal recovery standard. The reaction was started with the addition of $20 \mu \mathrm{l}\left[3-{ }^{14} \mathrm{C}\right] \mathrm{HMG}-\mathrm{CoA}$ (Amersham Corp., Arlington Heights, IL) diluted with unlabeled HMG-CoA to give $30 \mathrm{nmol}$ with a specific activity of $30 \mathrm{dpm} / \mathrm{pmol}$. The reaction was stopped after $10 \mathrm{~min}$ at $37^{\circ} \mathrm{C}$ with the addition of 20 $\mu \mathrm{l} 6 \mathrm{~N} \mathrm{HCl}$. After lactonization at $37^{\circ} \mathrm{C}$ for $30 \mathrm{~min}$, the products were separated by TLC on 0.25 -mm-thick silica gel 60 plates (E. Merck, Darmstadt, FRG), developed with benzene/acetone (1:1, vol/vol) and the radioactivity determined by liquid scintillation counting.

Data were subjected to statistical analysis that included the oneway analysis of variance and the unpaired $t$ test (19).

\section{Results}

The effects of Mev on endogenous bile-acid synthesis and the activities of HMGR and $\mathrm{CH} 7 \alpha \mathrm{H}$ in the bile-fistula rat are shown in Fig. 2. At least $10 \mathrm{~h}$ were necessary to drain the preexisting endogenous bile-acid pool. At this time, bile-acid synthesis began to increase and reached a maximum plateau $(2.7 \pm 0.2 \mu \mathrm{mol} / 100 \mathrm{~g}$ rat per $\mathrm{h})$ in $\sim 50 \mathrm{~h}$. Mevalonolactone was then infused at a rate of $154 \mu \mathrm{mol} / \mathrm{h}$ and no further increase in bile-acid output was observed (Fig. $2 a$ ). The infusion of mevalonolactone inhibited HMGR activity $90 \%$ (to $23 \pm 12$ from $230 \pm 43 \mathrm{pmol} / \mathrm{mg}$ protein per min, $P<0.001$ ) but did not affect $\mathrm{CH} 7 \alpha \mathrm{H}$ activity (Fig. $2 b$ ). Thus, bile-acid synthesis 

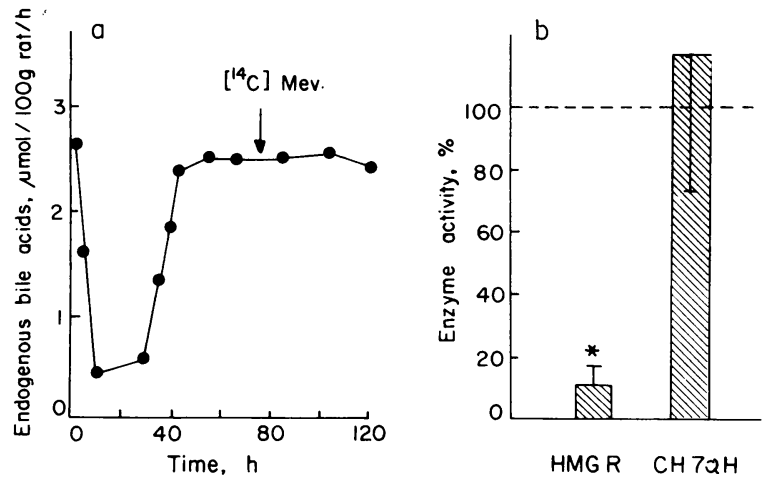

Figure 2. Effect of Mev on (a) endogenous bile-acid outputs and (b) hepatic microsomal HMGR and $\mathrm{CH} 7 \alpha \mathrm{H}$ activities in the bile-fistula rat. The endogenous bile-acid outputs were determined by capillary GLC and represented experiments with 12 bile-fistula rats (Fig. $2 a$ ). The rats were infused with $154 \mu \mathrm{mol} / \mathrm{h}\left[2-{ }^{14} \mathrm{C}\right] \mathrm{Mev}$ for up to $40 \mathrm{~h}$ after bile-acid synthesis reached a maximum plateau. Enzyme activities (Fig. $2 b$ ) were measured in duplicate in four bile fistula control rats (not receiving Mev, broken line) and four Mev-infused rats (bars) as detailed in the text. The means \pm SEM of HMGR and $\mathrm{CH} 7 \alpha \mathrm{H}$ which represent $100 \%$ activity in untreated control bile-fistula rats (broken line) were $230 \pm 43 \mathrm{pmol} / \mathrm{mg}$ protein per min and $196 \pm 42 \mathrm{pmol} / \mathrm{nmol}$ P-450 per min, respectively. ${ }^{*} P<0.001$.

was made independent of the rate-controlling enzyme of cholesterol biosynthesis, HMGR, by supplying Mev, a product of HMGR and precursor of cholesterol. Mev, administered in the stable form of mevalonolactone, provided endogenous cholesterol substrate for $\mathrm{CH} 7 \alpha \mathrm{H}$. It is important to emphasize that glucose, electrolytes, and rat chow were continuously supplied.

Fig. $3 a$ shows the effect of TCA on bile-acid synthesis. TCA infusion was begun after bile-acid outputs had reached a steady-state maximum during the infusion of supplemental $\left[2-{ }^{14} \mathrm{C}\right]$ mevalonolactone. At this point, all endogenous bile acids were labeled and in isotopic equilibrium (constant specific activity). When TCA was infused at a rate equivalent to the enterohepatic circulation of bile acids $(27 \mu \mathrm{mol} / 100 \mathrm{~g}$ rat per h) $(20,21)$, endogenous bile-acid formation was suppressed $82 \%$ (from $2.7 \pm 0.2$ to $0.5 \pm 0.1 \mu \mathrm{mol} / 100 \mathrm{~g}$ rat per $\mathrm{h}, P$ $<0.001)$ and remained inhibited throughout the infusion period. Furthermore, when TCA was discontinued, endogenous bile-acid outputs rose to the levels of control bile-fistula rats. $\mathrm{CH} 7 \alpha \mathrm{H}$ activity (Fig. $3 \mathrm{~b}$ ) that was measured at the nadir of endogenous bile-acid synthesis was inhibited $79 \%$ (from $201 \pm 38$ to $43 \pm 8 \mathrm{pmol} / \mathrm{nmol} \mathrm{P}-450$ per $\mathrm{min}, P<0.001$ ) and returned to derepressed values when TCA was discontinued. The marked inhibition of $\mathrm{CH} 7 \alpha \mathrm{H}$ by TCA was also observed when this enzyme activity was measured in the absence of endogenous sterols in a reconstituted assay system with acetone-treated microsomes (16). The inhibitory effect of TCA on $\mathrm{CH} 7 \alpha \mathrm{H}$ was not due to bile-acid toxicity as evidenced by the prompt return of $\mathrm{CH} 7 \alpha \mathrm{H}$ activity to pretreatment values. In addition, the specific activity of microsomal cholesterol remained constant during TCA infusion and was comparable to pre-TCA treatment values $(103 \pm 25$ and $96 \pm 26 \mathrm{dpm} / \mu \mathrm{g}$ cholesterol in TCA-infused rats at 74 and $114 \mathrm{~h}$ compared with $111 \pm 20 \mathrm{dpm} / \mu \mathrm{g}$ cholesterol in mevalonolactone-treated rats, $P>0.05$ ). This observation excludes the possibility of mobilization of unlabeled cholesterol by TCA to the endoplasmic reticulum leading to an underestimation of bile-acid synthesis
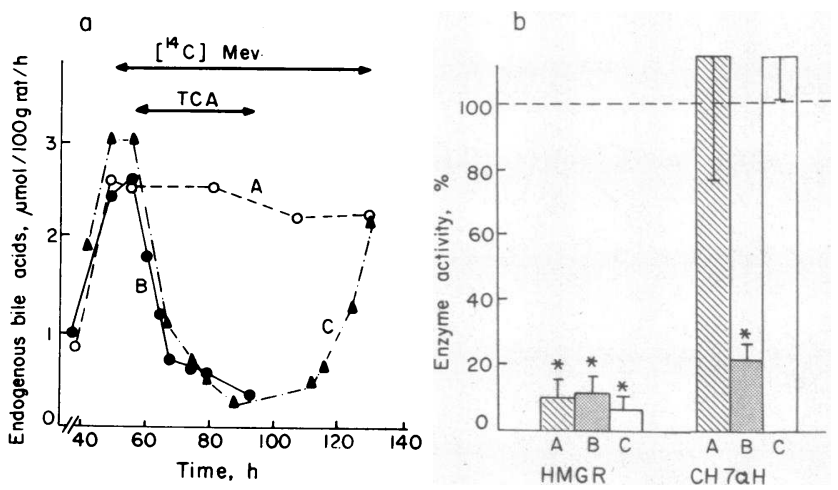

Figure 3. Effect of Mev and TCA on (a) endogenous bile-acid output and $(b)$ hepatic microsomal HMGR and $\mathrm{CH} 7 \alpha \mathrm{H}$ in the bile-fistula rat. The endogenous bile-acid outputs are from three representative experiments and were determined by capillary GLC with the exception that when TCA was infused, endogenous CA was calculated as described in Methods. In these experiments, rats were infused with $\left[{ }^{14} \mathrm{C}\right] \mathrm{Mev}(154 \mu \mathrm{mol} / \mathrm{h})$ throughout the experiments after depletion of the bile pool. In group A (open circles), only $\left[{ }^{14} \mathrm{C}\right] \mathrm{Mev}$ was administered to the bile-fistula rats, bile-acid outputs were measured throughout the experiment, and enzyme activities were determined at the end of the experimental period. In group B (solid circles), TCA was infused $(27 \mu \mathrm{mol} / 100 \mathrm{~g}$ rat per $\mathrm{h})$ after endogenous bile-acid synthesis had reached a maximum plateau. The animals were killed when endogenous bile-acid outputs were maximally inhibited and measurements of $\mathrm{HMGR}$ and $\mathrm{CH} 7 \alpha \mathrm{H}$ were determined. In group $\mathrm{C}$ (solid triangles), TCA infusion was discontinued after bile-acid synthesis had been suppressed and bile-acid outputs were measured during the recovery period. HMGR and $\mathrm{CH} 7 \alpha \mathrm{H}$ activities were determined in duplicate liver specimens from four control bile-fistula rats (broken line), four Mev rats $(A)$, eight $\mathrm{Mev}+\mathrm{TCA}$ rats $(B)$, and four $\mathrm{Mev}+$ TCA rats after discontinuation of TCA $(C)$. The means \pm SEM of HMGR and $\mathrm{CH} 7 \alpha \mathrm{H}$ activities that represent $100 \%$ in control rats (broken line) were: $230 \pm 43 \mathrm{pmol} / \mathrm{mg}$ protein per min and $196 \pm 42 \mathrm{pmol} / \mathrm{nmol} P-450$ per min, respectively. ${ }^{*} P<0.001$.
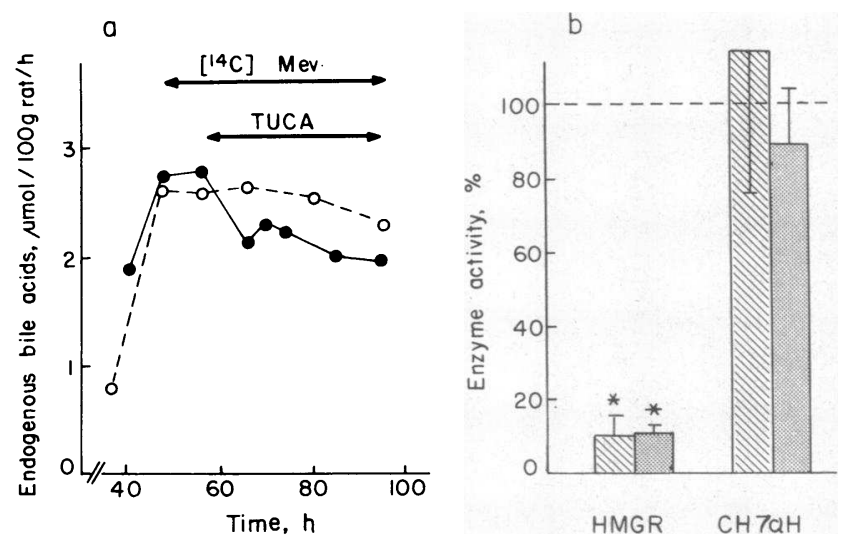

Figure 4. Effect of Mev and TUCA on (a) endogenous bile-acid output and $(b)$ hepatic microsomal HMGR and $\mathrm{CH} 7 \alpha \mathrm{H}$ in the bile-fistula rat. $\left[{ }^{14} \mathrm{C}\right] \mathrm{Mev}$ was infused continuously $(154 \mu \mathrm{mol} / \mathrm{h})$ to the Mev rats (open circles) and the Mev + TUCA rats (solid circles) after depletion of the bile pool. TUCA was administered at the rate of 27 $\mu \mathrm{mol} / 100 \mathrm{~g}$ rat per $\mathrm{h}$ and endogenous bile-acid outputs were determined by capillary GLC. Enzyme activities were measured in duplicate in four control bile-fistula rats (broken line), four Mev rats (hatched bars), and four Mev + TUCA rats (stippled bars). The means \pm SEM of HMGR and $\mathrm{CH} 7 \alpha \mathrm{H}$ activities that represent $100 \%$ in control rats (broken line) were $230 \pm 43 \mathrm{pmol} / \mathrm{mg}$ protein per min and $196 \pm 42 \mathrm{pmol} / \mathrm{nmol} \mathrm{P}-450$ per min, respectively. ${ }^{*} P<0.001$. 


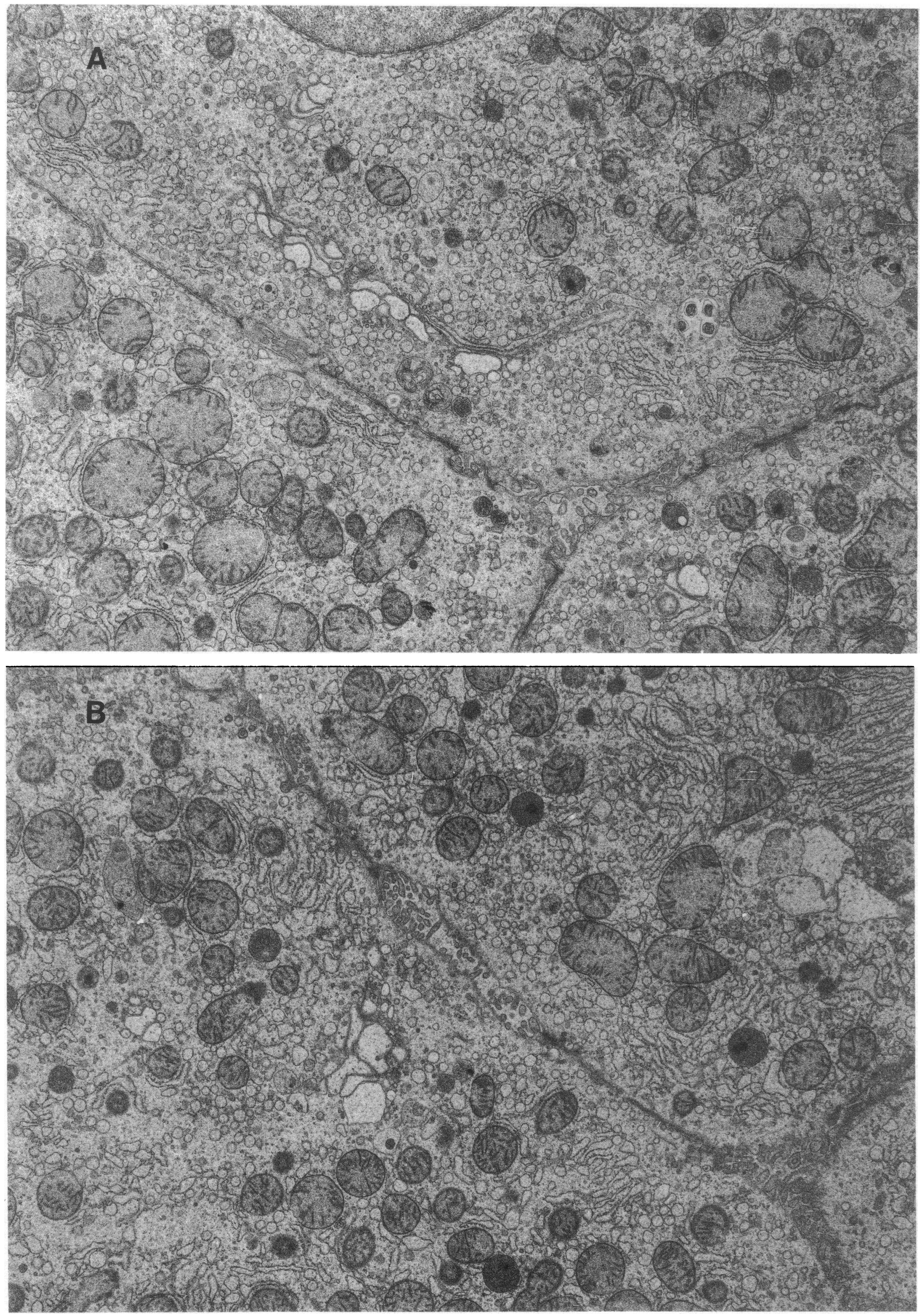




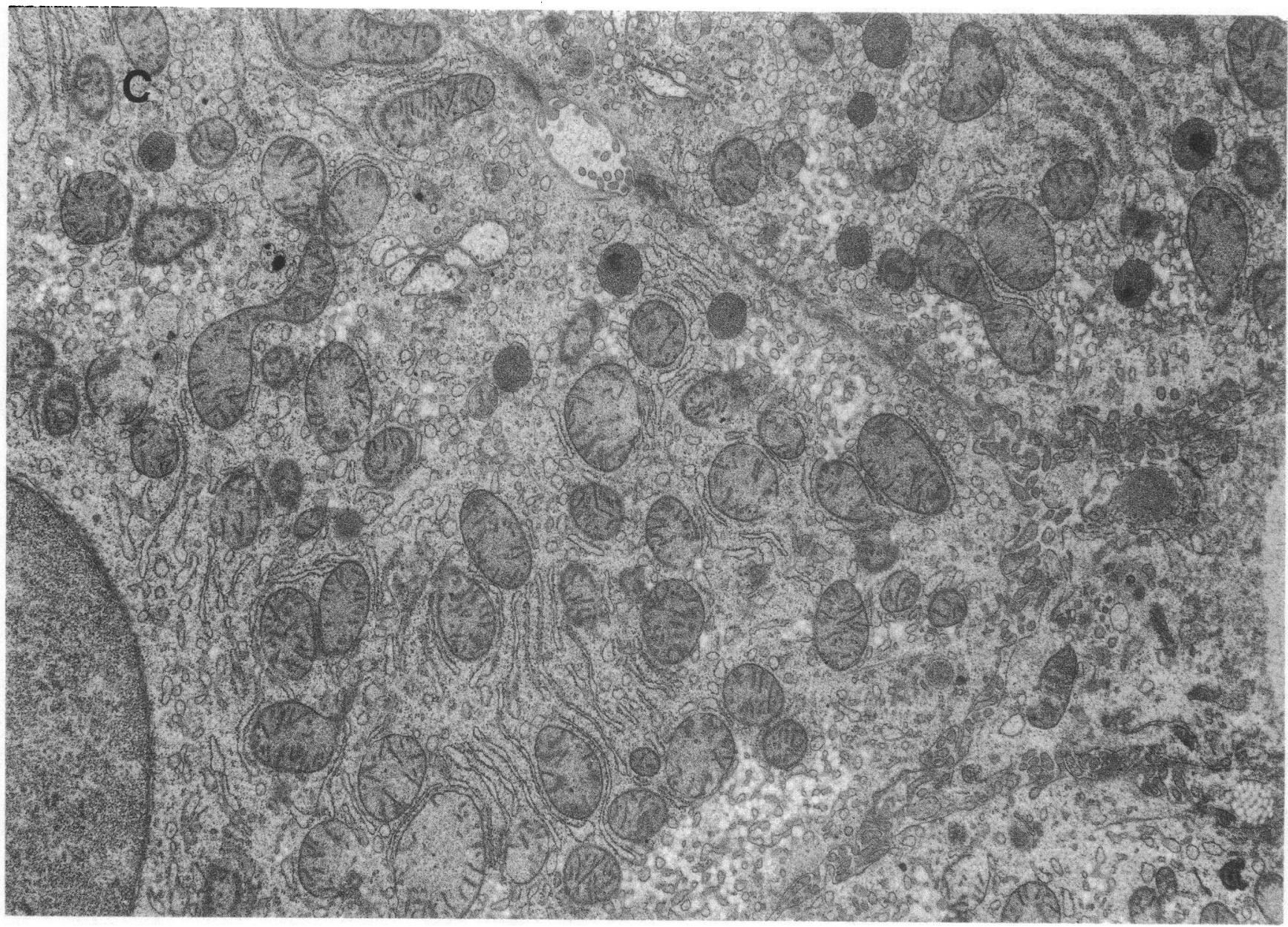

Figure 5. Electron microscopy of hepatocytes from bile-fistula rats: $(A) \mathrm{Mev}$ treatment ( $154 \mu \mathrm{mol} / \mathrm{h})$. Intact organelles with well-preserved bile canaliculi are shown. $(B) \mathrm{Mev}(154 \mu \mathrm{mol} / \mathrm{h})$ plus TCA $(27 \mu \mathrm{mol} / 100 \mathrm{~g}$ rat per $\mathrm{h})$ treatment. Well-preserved bile canaliculi and intact organelles comparable to the Mev rats. $(C) \mathrm{Mev}(154 \mu \mathrm{mol} / \mathrm{h})$ plus TUCA $(27 \mu \mathrm{mol} / 100 \mathrm{~g}$ rat per $\mathrm{h})$ treatment. Cytoarchitecture similar to that of the $\mathrm{Mev}$ and Mev + TCA rats. Proliferation of the smooth endoplasmic reticulum, vesiculated rough endoplasmic reticulum, and prominent Golgi vesicles are discernible in all specimens. Original magnification, 2,500.

due to a dilution of the specific activity of the substrate pool. HMGR activity remained suppressed throughout the mevalonolactone infusion (Fig. $3 \mathrm{~b}$ ) because mevalonolactone was continuously infused.

Fig. $4 a$ shows endogenous bile-acid outputs during TUCA infusion $(27 \mu \mathrm{mol} / 100 \mathrm{~g}$ rat per $\mathrm{h})$ in the maximally stimulated bile-fistula rat supplemented with $\left[2-{ }^{14} \mathrm{C}\right]$ mevalonolactone. After isotopic equilibrium had been attained in the bile acids, infusion of TUCA produced virtually no change in endogenous bile-acid output $(2.1 \pm 0.2$ vs. $2.7 \pm 0.2 \mu \mathrm{mol} / 100 \mathrm{~g}$ rat per h, $P>0.1) . \mathrm{CH} 7 \alpha \mathrm{H}$ activity during TUCA infusion also was not significantly reduced (to $174 \pm 30$ from $196 \pm 42 \mathrm{pmol} / \mathrm{nmol}$ P-450 per min, $P>0.1$ ) (Fig. $4 b$ ). HMGR activity remained inhibited during the entire mevalonolactone infusion period.

Light and electron microscopic examination of the hepatocytes of bile-fistula rats infused with Mev, Mev + TCA, or Mev + TUCA revealed comparable cytoarchitecture (Fig. 5, $A-C)$. Although there was no significant alteration in the liver cell organelles, there were early signs of vesiculation of rough endoplasmic reticulum and mild proliferation of smooth endoplasmic reticulum in bile acid-infused animals as well as controls.
Fig. 6 represents biliary bile-acid composition and outputs during mevalonolactone and bile-acid infusions that were measured when a steady-state for bile-acid synthesis had been attained. Neither endogenous bile-acid composition nor output changed during the administration of mevalonolactone. CA was the major bile acid (70\%) followed by chenodeoxycholic acid $(20 \%)$ and $\alpha$ - and $\beta$-muricholic acids (4\% and $5 \%$, respectively). During TCA infusion, the output of endogenous bile acids was markedly reduced (Fig. $6 b$ ) because of a decrease in the synthesis of the $7 \alpha$-hydroxylated bile acids, CA, chenodeoxycholic acid, and $\alpha$-muricholic acid (Fig. $6 a$ ). Conversely, the output of $\beta$-muricholic acid (a $7 \beta$-hydroxy bile acid) did not change significantly and represented $36 \%$ of the endogenous bile acids produced in the TCA-infused rats (Fig. $6 a$ ). More than $80 \%$ of the infused TCA was recovered in the bile (Fig. $6 b$ ) as evidenced by the mass of TCA with low radioactivity in the bile. During TUCA infusion, total endogenous bile-acid outputs did not change and were comparable to those of control and mevalonolactone-treated rats (Fig. $6 \mathrm{~b}$ ). However, endogenous bile-acid composition changed during TUCA infusion: CA was decreased (to $1.3 \pm 0.1$ from $1.9 \pm 0.2$ $\mu \mathrm{mol} / 100 \mathrm{~g}$ rat per $\mathrm{h}, P<0.05)$, whereas $\beta$-muricholic acid 

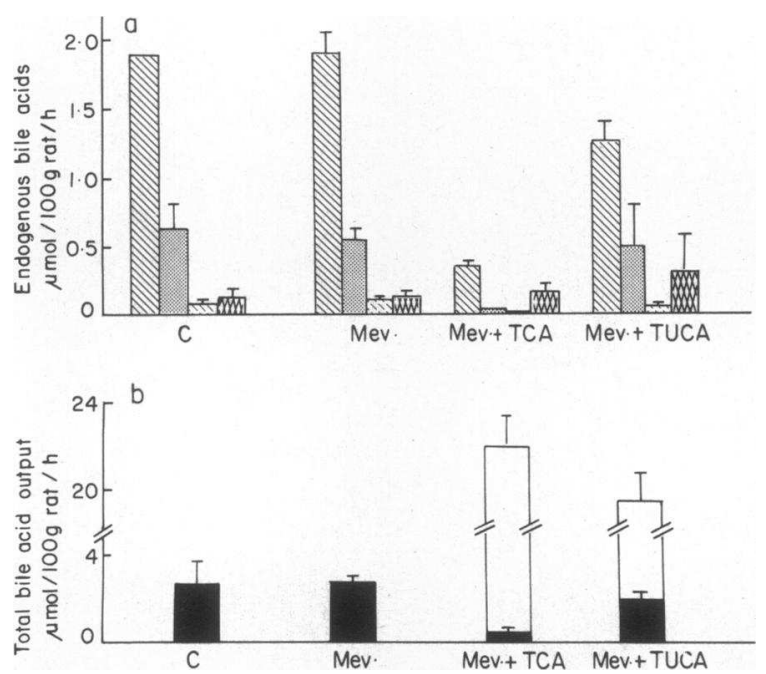

Figure 6. Effect of Mev, Mev + TCA, and Mev + TUCA on (a) hepatic bile-acid composition and $(b)$ total and endogenous bile-acid outputs in the bile-fistula rat. The control group $C(n=12)$ was infused only with the Ringer-Tyrode solution, whereas $\left[{ }^{14} \mathrm{C}\right] \mathrm{Mev}(154$ $\mu \mathrm{mol} / \mathrm{h}$ ) in Ringer-Tyrode solution was administered to the three other groups ( $n=4$ in each group). TCA and TUCA, where indicated, were infused at the rate of $27 \mu \mathrm{mol} / 100 \mathrm{~g}$ rat per $\mathrm{h}$ for $24 \mathrm{~h}$. Individual bile acids were determined by GLC but endogenous CA was quantitated during TCA infusion by TLC, GLC, and liquid scintillation counting as detailed in the text. The bars shown in $a$ represent: CA (hatched bars), chenodeoxycholic acid (stippled bars), $\alpha$ muricholic acid (broken line bars), and $\beta$-muricholic acid (diamond matrix bars). The solid and open bars $(b)$ represent endogenous and exogenous bile-acid outputs, respectively. Bile acid-treated rats were compared with the control group $C .{ }^{*} P<0.001 ;{ }^{\ddagger} P<0.05$.

increased (to $0.31 \pm 0.13$ from $0.14 \pm 0.04 \mu \mathrm{mol} / 100 \mathrm{~g}$ rat per $\mathrm{h}$, $P<0.05$ ). About $70 \%$ of the infused TUCA was recovered along with a small amount of unlabeled taurodeoxycholic acid that probably originated from the administered TUCA.

In Table I are listed biliary cholesterol outputs and hepatic cholesterol concentrations. Neither biliary cholesterol secretion nor hepatic cholesterol concentrations changed during

Table I. Effect of Mev, TCA, and TUCA on Biliary and Hepatic Cholesterol*

\begin{tabular}{|c|c|c|c|}
\hline \multirow[b]{2}{*}{ Treatment $^{\ddagger}$} & \multirow[b]{2}{*}{ Biliary cholesterol ${ }^{8}$} & \multicolumn{2}{|c|}{ Hepatic cholesterol ${ }^{8}$} \\
\hline & & Total & Esterified \\
\hline & $\mu \mathrm{mol} / 100 \mathrm{~g}$ rat per $h$ & $\mu \mathrm{mol} / \mathrm{g}$ liver & $\%$ \\
\hline Control & $0.11 \pm 0.02(4)$ & $5.5 \pm 0.7(5)$ & $8 \pm 2$ \\
\hline Mev & $0.13 \pm 0.02(15)$ & $5.9 \pm 0.5(5)$ & $27 \pm 3^{11}$ \\
\hline $\mathrm{Mev}+\mathrm{TCA}$ & $0.11 \pm 0.03(9)$ & $8.0 \pm 1.0^{11}(8)$ & $37 \pm 8^{\prime \prime}$ \\
\hline Mev + TUCA & $0.12 \pm 0.03(4)$ & $6.6 \pm 1.4(5)$ & $25 \pm 10^{\prime \prime}$ \\
\hline
\end{tabular}

* Values shown are means \pm SEM. Numbers in parentheses represent numbers of bile-fistula rats studied.

${ }^{\ddagger} \mathrm{Mev}$ and bile acids were infused at the rate of $154 \mu \mathrm{mol} / \mathrm{h}$ and 27 $\mu \mathrm{mol} / 100 \mathrm{~g}$ rat per $\mathrm{h}$, respectively.

${ }^{\S}$ Biliary and hepatic cholesterol were determined by TLC and GLC as detailed in the text.

"Significantly higher than the value for the control group, $P<0.001$. mevalonolactone infusion. When mevalonolactone and TCA were infused, hepatic cholesterol rose 45 and $36 \%$ relative to control and mevalonolactone-infused rats, respectively $(P$ $<0.01)$. The proportion of esterified cholesterol was increased by the infusion of mevalonolactone $(P<0.001)$ and was further increased by TCA, although neither the bile flow nor biliary cholesterol outputs changed. TUCA infusion did not affect either hepatic cholesterol concentration or the output of biliary cholesterol.

\section{Discussion}

The results of these experiments conclusively demonstrate that TCA infused intraduodenally at a rate that replaces the enterohepatic flux inhibits endogenous bile-acid synthesis. Further, TUCA, the $7 \beta$-hydroxy epimer of TCA, was not inhibitory at the same concentration, which emphasizes the importance of the orientation of the hydroxyl group at C-7. The inhibitory effect of TCA on bile-acid synthesis was mediated by suppression of the rate-controlling enzyme, $\mathrm{CH} 7 \alpha \mathrm{H}$, which catalyzes the conversion of cholesterol to $7 \alpha$-hydroxycholesterol. Divergent and often contradictory results concerning the effect of bile acids on endogenous bile-acid synthesis in the bile-fistula rat have been reported recently by several investigators $(8,9,22,23)$. These investigations could not consistently demonstrate feedback inhibition of bile-acid synthesis when TCA was infused either intraduodenally or intravenously. A major problem in demonstrating inhibition of bileacid synthesis has been a failure to infuse sufficient amounts of bile acids to the bile-fistula rat. According to Shefer et al. (11) bile-acid synthesis was not inhibited consistently until 20 $\mu \mathrm{mol} / 100 \mathrm{~g}$ rat per $\mathrm{h}$ was infused. This rate of bile-acid flux through the liver is necessary to replace the normal enterohepatic circulation of bile acids $(11,20,21)$. Furthermore, Duane et al. (9) attributed the suppression of bile-acid synthesis during infusion of TCA at $10 \mu \mathrm{mol} / 100 \mathrm{~g}$ rat per $\mathrm{h}$ to electrolyte loss and a lack of bicarbonate supplementation. In this study, when bicarbonate was added to the electrolyte-glucose solution to prevent dehydration and acidosis, and TCA was infused at the rate of $27 \mu \mathrm{mol} / 100 \mathrm{~g}$ rat per $\mathrm{h}$, marked inhibition of bile-acid synthesis was observed. That this effect was not due to liver toxicity was evidenced in Fig. 5, which shows no morphologic liver damage. Furthermore, discontinuation of TCA infusion when bile-acid synthesis was maximally suppressed resulted in a return of bile-acid production to the level found in the control bile-fistula rats.

Our findings clearly showed a major difference between TCA and TUCA. Although the mechanism for bile-acid feedback inhibition remains unknown, the $7 \alpha$-hydroxy group was apparently necessary to elicit a response because identical concentrations of both bile acids were infused. Earlier, Shefer et al. (6) suggested that TCA inhibited bile-acid synthesis via the suppression of $\mathrm{CH} 7 \alpha \mathrm{H}$, but these results were confounded by similar changes in HMGR. Thus, reduced bile-acid synthesis could have reflected decreased availability of cholesterol for it is unequivocally established in mammals that cholesterol is the sole precursor of bile acids (1). In this experimental design, newly synthesized cholesterol was provided by infusing mevalonolactone so that bile-acid synthesis could be studied independently of the activity of HMGR, the rate-controlling enzyme of cholesterol synthesis. As expected, HMGR activity 
was induced 6-10-fold by the interruption of the enterohepatic circulation of bile acids (e.g., establishment of the bile fistula) and inhibited by the administration of mevalonolactone, which was converted to cholesterol. However, bile-acid synthesis and $\mathrm{CH} 7 \alpha \mathrm{H}$ activity remained elevated during the mevalonolactone infusion. The uncoupling of bile-acid synthesis from HMGR activity strengthened the premise that TCA exerts feedback inhibition via a direct suppression of $\mathrm{CH} 7 \alpha \mathrm{H}$ activity whether or not there is a secondary effect of limiting cholesterol supply.

The administration of TUCA did not significantly decrease total endogenous bile-acid output (Figs. $4 a$ and $6 b$ ) or $\mathrm{CH} 7 \alpha \mathrm{H}$ activity (Fig. $4 \mathrm{~b}$ ). Apparently, the $7 \beta$-hydroxy bile acid is unable to exert feedback inhibition of $\mathrm{CH} 7 \alpha \mathrm{H}$, and endogenous bile-acid synthesis remains elevated. Similar results have been reported by Nilsell et al. (24), who compared the effects of CDCA and its $7 \beta$-hydroxy epimer UDCA in humans, and by Heuman et al. (25), who studied the effect of bile-acid feeding on enzymes regulating hepatic cholesterol and bile-acid synthesis in the rat. The mechanism by which bile acids suppress bile-acid synthesis and $\mathrm{CH} 7 \alpha \mathrm{H}$ activity is not known. Heuman et al. (25) suggested that the hydrophilic-hydrophobic balance in the bile-acid pool may be the critical factor in this regulatory process.

An interesting new observation was the continued formation of $\beta$-MCA noted during the TCA infusion when the outputs of the $7 \alpha$-hydroxylated bile acids (CA, CDCA, and $\alpha$-MCA) were depressed (Fig. 6). Since the enterohepatic circulation was completely interrupted, the $\beta$-MCA was synthesized by the liver. It is possible that $\beta$-MCA was synthesized from $\alpha$-MCA (26). Alternatively, cholesterol could be $7 \beta$-hydroxylated and converted to $\beta$-MCA by a hitherto unrecognized pathway as suggested for UDCA in the nutria by Tint et al. (27). Nevertheless, the bile fistula excludes bacterial bileacid metabolism as a mechanism for $\beta$-MCA formation. During TUCA infusion, individual bile-acid outputs were similar to the control and mevalonolactone-treated rats, except that the proportions of CA declined and $\beta$-MCA rose.

Another important difference between TCA and TUCA relates to their effect on hepatic cholesterol concentration. During TCA infusion, hepatic cholesterol concentrations rose $36 \%$, whereas TUCA infusion had no effect. Therefore, the inhibition of bile-acid synthesis leads to the accumulation of cholesterol in the liver. It is noteworthy that hepatic cholesterol secretion did not change during the administration of both TCA and TUCA. Although other investigators $(10,23)$ have reported that TCA was choleretic and increased hepatic cholesterol secretion, these effects were not observed during the administration of TCA or TUCA with mevalonolactone. The absent choleresis might be related to the administered mevalonolactone.

To summarize, $\mathrm{CH} 7 \alpha \mathrm{H}$ and bile-acid synthesis were upregulated by the interruption of the enterohepatic circulation, and bile-acid synthesis could not be further increased by the administration of $154 \mu \mathrm{mol} / \mathrm{h}$ of mevalonolactone. When physiological amounts of the sodium salt of taurocholic acid ( $7 \alpha$-hydroxy bile acid) were infused for $24 \mathrm{~h}$, the synthesis of endogenous $7 \alpha$-hydroxy bile acids was markedly inhibited because of the suppression of $\mathrm{CH} 7 \alpha \mathrm{H}$. Substituting an equal amount of the sodium salt of tauroursocholic acid (the $7 \beta$-hydroxy epimer of cholic acid) was ineffective in downregulating bile-acid synthesis.

\section{Acknowledgments}

The skillful technical assistance of Ms. S. Hauser, E. Paroulek, V. Packin, and S. Lerner is gratefully acknowledged.

This work is supported in part by U. S. Public Health Service grants DK-26756, HL-17818, and DK-18707.

\section{References}

1. Danielsson, H. 1973. Mechanism of bile acid biosynthesis. In The Bile Acids. P. P. Nair and D. Kritchevsky, editors. Plenum Publishing Corp., New York. 1-27.

2. Shefer, S., F. G. Zaki, and G. Salen. 1983. Early morphologic and enzymatic changes in livers of rats treated with chenodeoxycholic and ursodeoxycholic acids. Hepatology (Baltimore). 3:201-208.

3. Shefer, S., S. Hauser, I. Bekersky, and E. H. Mosbach. 1970. Biochemical site of regulation of bile acid biosynthesis in the rat. $J$. Lipid Res. 11:404-411.

4. Einarsson, K., K. Hellström, and M. Kallner. 1973. Feedback regulation of bile acid formation in man. Metab. Clin. Exp. 22:14771486.

5. Reinhard, M. P., J. T. Billheimer, J. R. Faust, and J. L. Gaylor. 1987. Subcellular localization of the enzymes of cholesterol biosynthesis and metabolism in rat liver. J. Biol. Chem. 262:9649-9655.

6. Shefer, S., S. Hauser, V. Lapar, and E. H. Mosbach. 1973. Regulatory effects of sterols and bile acids on hepatic 3-hydroxy-3-methylglutaryl CoA reductase and cholesterol $7 \alpha$-hydroxylase in the rat. $J$. Lipid Res. 14:573-580.

7. Danielsson, H., K. Einarsson, and G. Johansson. 1967. The effect of biliary drainage on individual reactions in the conversion of cholesterol to taurocholic acid. Eur. J. Biochem. 2:44-49.

8. Pries, J. M., A. Gustafson, D. Wiegard, and W. C. Duane. 1983. Taurocholate is more potent than cholate in suppression of bile acid synthesis in the rat. J. Lipid Res. 24:141-146.

9. Duane, W. C., A. O. McHale, and J. N. Hamilton. 1988. Studies of feedback suppression of bile salt synthesis in the bile fistula rat. $J$. Lipid Res. 29:212-214.

10. Heuman, D. M., C. R. Hernandez, P. B. Hylemon, W. M. Kabaska, C. Hartman, and Z. R. Vlahcevic. 1988. Regulation of bile acid synthesis. I. Effects of conjugated ursodeoxycholate and cholate on bile acid synthesis in chronic bile fistula rats. Hepatology (Baltimore). 8:358-365.

11. Shefer, S., S. Hauser, I. Bekersky, and E. H. Mosbach. 1969. Feedback regulation of bile acid biosynthesis in the rat. J. Lipid Res. 10:646-655.

12. Tserng, K. Y., D. L. Hackey, and P. D. Klein. 1977. An improved procedure for the synthesis of glycine and taurine conjugates of bile acids. J. Lipid Res. 18:404-407.

13. Nguyen, L. B., S. Shefer, G. Salen, I. Horak, G. S. Tint, and D. J. McNamara. 1988. The effect of abnormal plasma and cellular sterol content and composition on low density lipoprotein uptake and degradation by monocytes and lymphocytes in sitosterolemia with xanthomatosis. Metab. Clin. Exp. 37:346-351.

14. Shefer, S., G. Salen, and A. K. Batta. 1986. Methods of assay. In Cholesterol $7 \alpha$-Hydroxylase ( $7 \alpha$-Monooxygenase). R. Fears and J. R. Sabine, editors. CRS Press, Inc., Boca Raton, FL. 43-49.

15. Yasukochi, Y., and B. S. S. Masters. 1976. Some properties of a detergent-solubilized NADPH-cytochrome c (cytochrome P450) reductase purified by biospecific affinity chromatography. J. Biol. Chem. 251:5337-5344.

16. Shefer, S., G. Salen, L. Nguyen, A. K. Batta, V. Packin, G. S. Tint, and $S$. Hauser. 1988. Competitive inhibition of bile acid synthesis by endogenous cholestanol and sitosterol in sitosterolemia with xanthomatosis: effect on cholesterol $7 \alpha$-hydroxylase. J. Clin. Invest. 82:1833-1839.

17. Shefer, S., F. W. Cheng, S. Hauser, A. K. Batta, and G. Salen. 1981. Regulation of bile acid synthesis. Measurement of cholesterol 
$7 \alpha$-hydroxylase activity in rat liver microsomal preparations in the absence of endogenous cholesterol. J. Lipid Res. 22:532-536.

18. Harwood, H. J., Jr., M. Schneider, and P. W. Stacpoole. 1984. Regulation of human leukocyte microsomal hydroxymethylglutarylCoA reductase activity by a phosphorylation and dephosphorylation mechanism. Biochim. Biophys. Acta. 805:245-251.

19. Mendenhall, W. 1975. Introduction to Probability and Statistics. Wadsworth Publishing Company, Inc., Belmont, CA. 457 pp.

20. Weis, E. E., and C. A. Barth. 1978. The extracorporeal bile duct. A new model for determination of bile flow and bile composition in the intact rat. J. Lipid Res. 19:856-862.

21. Kuipers, F., R. Kavinga, H. Basochieter, G. P. Toorop, F. R. Hindriles, and R. J. Vonk. 1985. Enterohepatic circulation in the rat. Gastroenterology. 88:403-411.

22. Davis, R. A., C. A. Musso, M. Malone-McNeal, G. R. Lattier, P. M. Hyde, J. Archambault-Schexnayder, and M. Straka. 1988. Examination of bile acid negative feedback regulation in rats. J. Lipid Res. 29:202-211.

23. Stange, E. F., J. Scheibner, C. Lutz, and H. Ditschuneit. 1988.
Feedback regulation of bile acid synthesis in the rat by dietary vs. intravenous cholate or taurocholate. Hepatology (Baltimore). 8:879886.

24. Nilsell, K., B. Angelin, B. Leijd, and K. Einarsson. 1983. Comparative effects of ursodeoxycholic acid and chenodeoxycholic acid on bile acid kinetics and biliary lipid secretion in humans. Gastroenterology. 85:1248-1256.

25. Heuman, D. M., Z. R. Vlahcevic, M. L. Bailey, and P. B. Hylemon. 1988. Regulation of bile acid synthesis. II. Effect of bile acid feeding on enzymes regulating hepatic cholesterol and bile acid synthesis in the rat. Hepatology (Baltimore). 8:892-897.

26. Elliott, W. H. 1985. Metabolism of bile acids in liver and extrahepatic tissues. In Sterols and Bile Acids. H. Danielsson and J. Sjövall, editor. Elsevier Science Publishers B. V., Amsterdam, Netherlands. 303-329.

27. Tint, G. S., J. Bullock, A. K. Batta, S. Shefer, and G. Salen. 1986. Ursodeoxycholic acid, 7-ketolithocholic acid and chenodeoxycholic acid are primary bile acids in the nutria (Myocastor coypus). Gastroenterology. 90:702-709. 